\title{
Development and Flight Results of Solid Propulsion System for Enhanced Epsilon Launch Vehicle
}

\author{
By Koki Kitagawa, ${ }^{1)}$ Shinichiro Tokudome, ${ }^{1)}$ Keiichi Hori, ${ }^{1)}$ \\ Haruhito TANNO, ${ }^{2)}$ and Nobuyuki NAKANO ${ }^{2)}$ \\ 1) Institute of Space and Astronautical Science, JAXA, Sagamihara, Japan \\ ${ }^{2)}$ Solid Propulsion Office, Rocket Systems Department, IHI Aerospace, Tomioka, Japan
}

(Received June 23rd, 2017)

\begin{abstract}
The development of enhanced propulsion system for the next Epsilon rocket was progressed. The development of Enhanced Epsilon is mainly the renewal of the second stage, and also includes each subsystem's improvement. The second stage motor M-35 was newly designed and manufactured. In order to verify the design, the static firing test of the second motor M-35 under the condition of vacuum ambient was conducted in 2015. The JAXA successfully launched the first Enhanced Epsilon launch vehicle. All solid propulsion systems for the Enhanced Epsilon launch vehicle showed a very good behavior during the flight.
\end{abstract}

Key Words: Solid Rocket Motor, Solid Propellant, M-35, Static Firing Test

\section{Introduction}

The Epsilon launch vehicle, the newest version of Japan's solid propulsion rocket, made its maiden flight in September of 2013. The purpose of the Epsilon rocket is to provide small satellites with responsive launching with low-cost, user-friendly and efficient launch system. ${ }^{1), 2)}$ After the first flight was successfully finished, JAXA has been conducting intensive researches on a next generation Epsilon to launch a more powerful version of Epsilon. JAXA has started the development of Enhanced Epsilon. The features of the Enhanced Epsilon are increase of launch capacity and enlargement of payload usable volume. In order to realize these improvements, powerful second stage motor (M-35 motor) is newly developed and exposed outside the nose fairing.

This paper describes the detail of development of the second stage motor and flight results of solid propulsion system for the Enhanced Epsilon launch vehicle.

\section{Enhanced Epsilon Launch Vehicle}

Figure 1 shows schematic of the Enhanced Epsilon. Basic specifications of the Enhanced Epsilon launch vehicle and its main propulsion systems are listed in Table 1 . The vehicle is normally three-stage and all-solid rocket weighing 95 metric tons and can carry $590 \mathrm{~kg}$ of small satellite into sun-synchronous orbit (SSO) of $500 \mathrm{~km}$ altitudes. As optional configuration, a liquid propulsion system is equipped to the third stage for missions requiring precision orbit injection.

Main points of modification of solid propulsion systems from the initial version of Epsilon are mentioned below. About the $2^{\text {nd }}$ stage, the outside diameter of the motor case which was equipped inside the fairing is expanded to approximately $2.6 \mathrm{~m}$ in order to increase the acceptable amount of the solid propellant and the outer shell of the motor case is used as the outer shell of the launch vehicle (Exposing). A development policy is compatibility of high-performance required for an upper-stage motor and cost reduction. The second stage motor is developed using the latest design technique and new developed material.

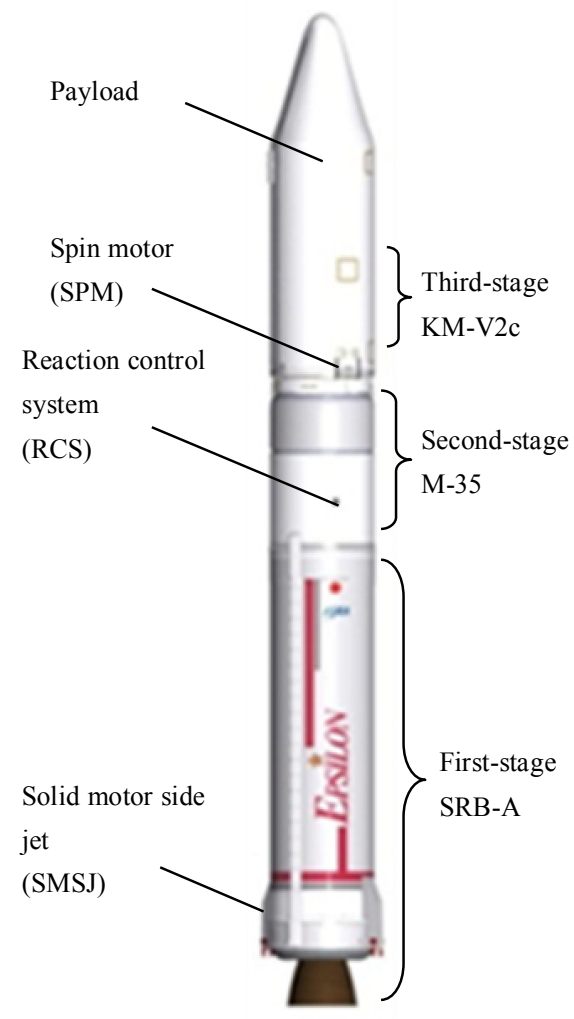

Fig. 1. Schematic of the Enhanced Epsilon. 
Table 1. Basic specifications of the Enhanced Epsilon and its solid propulsion systems. ${ }^{3)}$

\begin{tabular}{|c|c|c|}
\hline \multicolumn{2}{|l|}{ Item } & Planed value \\
\hline \multicolumn{2}{|c|}{ Vehicle with option lift-off mass } & 95 ton \\
\hline \multicolumn{2}{|c|}{ Launch capability (@SSO500km) } & More than \\
\hline $\begin{array}{l}1^{\text {st }} \text { satage } \\
\text { (Three-axis attitude control } \\
\text { : MNTVC/SMSJ) }\end{array}$ & $\begin{array}{l}\text { Total mass } \\
\text { (payload fairing } \\
\text { included) }\end{array}$ & 76 ton \\
\hline SRB-A & Propellant mass & 66.0 ton \\
\hline \multicolumn{3}{|l|}{ Main motor } \\
\hline & $\begin{array}{l}\text { Burning } \\
\text { duration }\end{array}$ & $120 \mathrm{~s}$ \\
\hline & $\begin{array}{l}\text { Specific } \\
\text { impulse* }\end{array}$ & $283.6 \mathrm{~s}$ \\
\hline \multirow[t]{3}{*}{ SMSJ x 2} & Propellant mass & $\begin{array}{l}50 \mathrm{~kg} \\
\text { (each) }\end{array}$ \\
\hline & Thrust* & $\begin{array}{c}\text { More than } \\
270 \mathrm{~N}\end{array}$ \\
\hline & $\begin{array}{l}\text { Operating } \\
\text { duration }\end{array}$ & $\begin{array}{c}\text { More than } \\
171 \mathrm{~s}\end{array}$ \\
\hline \multirow{5}{*}{$\begin{array}{l}2^{\text {nd }} \text { stage } \\
\text { (Three-axis attitude control } \\
\text { : MNTVC/Gas jet) } \\
\text { M-35 } \\
\text { Main motor }\end{array}$} & Total mass & 16 ton \\
\hline & Propellant mass & 15 ton \\
\hline & & \\
\hline & $\begin{array}{l}\text { Specific } \\
\text { impulse* }\end{array}$ & $295 \mathrm{~s}$ \\
\hline & $\begin{array}{l}\text { Burning } \\
\text { duration }\end{array}$ & $129 \mathrm{~s}$ \\
\hline \multirow[t]{3}{*}{$\begin{array}{l}\text { SPM } \times 2 \\
\text { Spin motor }\end{array}$} & Propellant mass & $\begin{array}{l}1.6 \mathrm{~kg} \\
(\mathrm{each})\end{array}$ \\
\hline & Thrust* & $0.85 \mathrm{kN}$ \\
\hline & $\begin{array}{l}\text { Operating } \\
\text { duration }\end{array}$ & $4.8 \mathrm{~s}$ \\
\hline $\begin{array}{l}3^{\text {rd }} \text { stage } \\
(\text { Spin control })\end{array}$ & Total mass & 3 ton \\
\hline $\begin{array}{l}\text { KM-V2c } \\
\text { Main Motor }\end{array}$ & Main Motor & 2.5 ton \\
\hline & Thrust* & $80.5 \mathrm{kN}$ \\
\hline & $\begin{array}{l}\text { Burning } \\
\text { duration } \\
\end{array}$ & $91.1 \mathrm{~s}$ \\
\hline & $\begin{array}{l}\text { Specific } \\
\text { impulse* }\end{array}$ & $299 \mathrm{~s}$ \\
\hline TRM & Propellant mass & $0.04 \mathrm{~kg}$ \\
\hline \multicolumn{3}{|l|}{ Tumble Motor } \\
\hline & Total impulse* & $91 \mathrm{~N} \cdot \mathrm{s}$ \\
\hline
\end{tabular}

\section{Development of $2^{\text {nd }}$ Stage Main Motor (M-35) ${ }^{3)}$}

\subsection{Solid propellant}

Solid propellant which can be the high-performance equal to a conventional upper-stage motor developed newly, with cost reduction. Specifically, materials for propellant are reselected based on the cost and market availability, and the material combination which can lead to the best performance and slight adjustment method of the burning rate is adopted.

An achieved perspective is obtained at present. The static firing test, which is mentioned in Section 3, to verify the performance was conducted with a full-scale motor.

\subsection{Igniter}

A general front ignition system is adopted instead of the rear ignition system of the throw-away type which was adopted for the previously used motor. Compatibility of high-performance and cost reduction is achieved by communization of the material with the main motor. The development is being advanced, considering the design with which a part of the high reliable igniter for the $1^{\text {st }}$ stage can be shared.

Tests using a prototype model was conducted and the verification of the performance was completed. The static firing test, which is mentioned in Section 3, was conducted for the final verification of ignition function to the main motor.

\subsection{Case insulation}

A newly developed material is applied to the case insulation. This material has heat-resisting property as much as the previously used material and also has airtightness and water-tightness. In the past, it was necessary to laminate the airtight material and the water tight material additionally for the pressure-resistant test and keeping airtightness. However, the new material can reduce the insulation to one layer. Therefore, it can be compatible that performance improvement by weight reduction and cost reduction by reduction in manufacturing process.

The development of the new material and the verification tests were completed. The final verification include burnout characteristic was conducted with the static firing test, which is mentioned in Section 3.

\subsection{Nozzle}

An extendable nozzle is not adopted due to compatibility of high-performance and cost reduction. The nozzle which can achieve a necessary specific impulse is designed. As the result of an optimization of a profile inside the nozzle based on the technique which was accumulated by motor development in the past, the nozzle expansion ratio is approximately 50 and average specific impulse achieves $295 \mathrm{~s}$.

The static firing test, which is mentioned in Section 3, was conducted for the final verification of the nozzle design.

\section{M-35 Static Firing Test ${ }^{4}$}

M-35 static firing test was conducted to verify the design and performance of M-35 motor finally with full scale motor. The static firing test was conducted in middle-altitude test stand (MATS) in Noshiro rocket testing center. Main purpose and action items are shown in Table 2. 
Table 2. Main purpose and action items.

\begin{tabular}{ll}
\hline Main purpose & Action item \\
\hline Technical verification & $\begin{array}{l}\text { Confirmation of propulsion } \\
\text { characteristics }\end{array}$ \\
\cline { 2 - 2 } & Verification of thermal insulation design \\
\hline & Verification of structural design \\
\hline & Confirmation of TVC function \\
\hline & $\begin{array}{l}\text { Confirmation of measurement system } \\
\text { and vibration characteristics } \\
\text { (hammering test, acoustic test) }\end{array}$ \\
\cline { 2 - 2 } Confirmation of workability of motor \\
assembly operation
\end{tabular}

\subsection{M-35 motor for static firing test}

Because main purpose of the static firing test is the final verification of M-35 motor development, basically the specifications of the prototype model (test motor) are the same specifications as the flight model. However, some specifications are different due to constraints on testing and data obtaining. Differences of the specifications between the prototype model (PM) and flight model (FM) are shown in Table 3. Figure 2 shows schematic of the prototype model and Table 4 shows its main characteristics.

Table 3. Differences of the specifications between the prototype model and flight model.

\begin{tabular}{llll}
\hline \multirow{2}{*}{ Items } & \multicolumn{2}{c}{ Specification } & $\begin{array}{l}\text { Purpose } \\
\text { Reason }\end{array}$ \\
\cline { 2 - 4 } & FM & PM & Adaption to MATS. \\
\hline $\begin{array}{l}\text { Nozzle expansion } \\
\text { ratio }\end{array}$ & 50 & 25 & $\begin{array}{l}\text { Adjustment to diffuser } \\
\text { interface }\end{array}$ \\
\hline $\begin{array}{l}\text { TVC } \\
\text { reference rod }\end{array}$ & 2 & 3 & $\begin{array}{l}\text { Rudder angle } \\
\text { measurement }\end{array}$ \\
\hline $\begin{array}{l}\text { Pressure } \\
\text { measurement port }\end{array}$ & 1 & 5 & $\begin{array}{l}\text { Evaluation of ignition } \\
\text { delay. } \\
\text { Back-up }\end{array}$ \\
\hline Quench port & N/A & 2 & $\begin{array}{l}\text { Inhibition of spread of } \\
\text { fire after burning }\end{array}$ \\
\hline
\end{tabular}

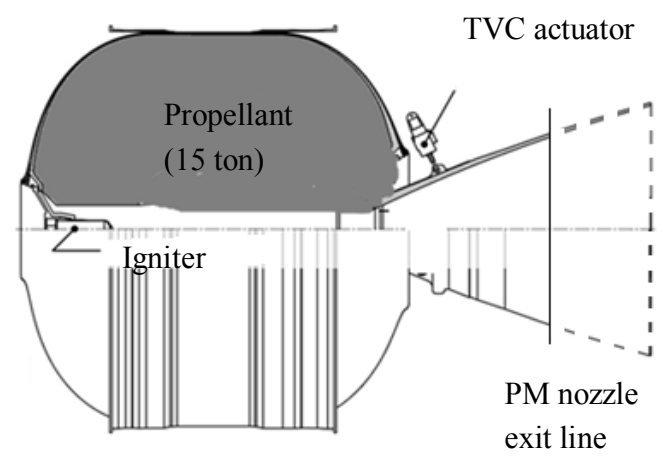

Fig. 2. Schematic of M-35 (PM).

Table 4. M-35 PM main characteristics.

\begin{tabular}{ll}
\hline Length & $3.2 \mathrm{~m}$ \\
\hline Outer diameter & $2.5 \mathrm{~m}$ \\
\hline Total weight & $16 \mathrm{ton}$ \\
\hline Propellant weight & $15 \mathrm{ton}$ \\
\hline Specific impulse (prediction) & $282 \mathrm{~s}$ \\
\hline
\end{tabular}

\subsection{Systems of static firing test}

The firing test was conducted under the condition of initial ambient pressure approximately 140 Torr. Figure 3 shows schematic of the static firing test system. The exhaust gas diffuser with double cylinder was used in order to keep low ambient pressure during firing. The ambient pressure is kept by making shock waves in the exhaust gas diffuser. Because it is heated by exhaust gas, it is cooled by water flow in the double cylinder. The cooling water is supplied from the water tank and the mass flow rate is controlled by PID controller. During firing, the TVC (Thrust vector control) nozzle is actuated and TVC function is confirmed. The sensors around the motor are connected to the data-loggers in the control room through the airtight relay panel. In order to inhibit the spread of fire after burning, air flow into the motor case is obstructed as well as the motor case and the nozzle are cooled with $\mathrm{CO}_{2}$ injection into the motor case from headend of the motor.

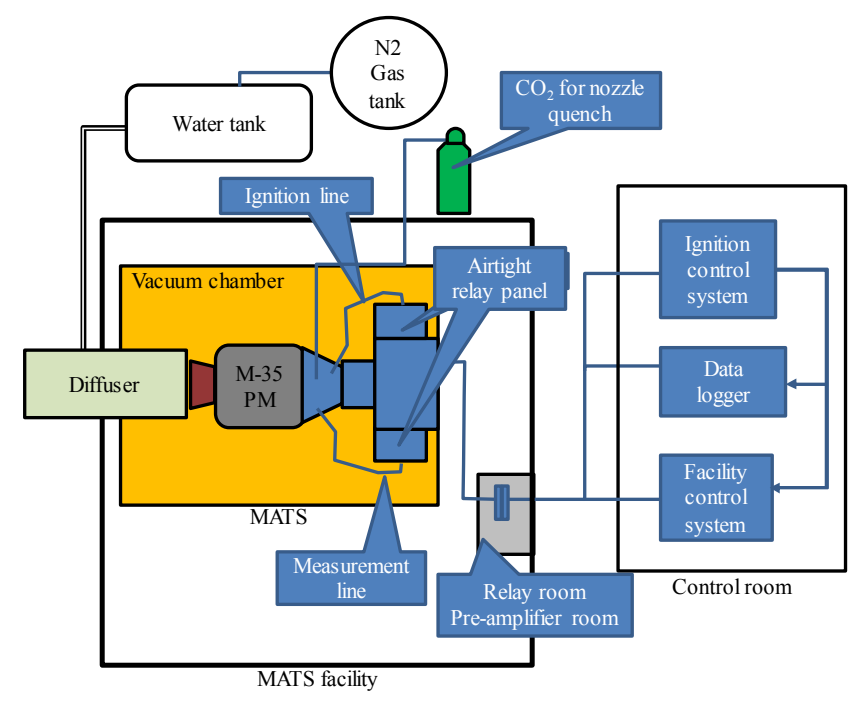

Fig. 3. Schematic of static firing test system. 


\subsection{Results of static firing test}

The M-35 static firing test was successfully performed at Noshiro rocket testing center on December $21^{\text {st }}, 2015$. Table 5 shows environmental conditions at the test.

Table 5. Environmental conditions.

\begin{tabular}{ll}
\hline Weather & Cloudiness \\
\hline Atmospheric temperature & $6.5 \mathrm{degC}$ \\
\hline Atmospheric pressure & $1020 \mathrm{hPa}$ \\
\hline Wind direction & East \\
\hline Wind velocity & $2.5 \mathrm{~m} / \mathrm{s}$ \\
\hline Propellant temperature & $13.6 \mathrm{degC}$ \\
\hline Initial ambient pressure & 143 torr $(19 \mathrm{kPa})$ \\
\hline
\end{tabular}

Chamber pressure $(\mathrm{Pc})$ and igniter pressure $(\mathrm{Pig})$ in transition region at the ignition is shown in Fig. 4. It was confirmed that the ignition was rapid and stable and quench did not occur. The combustion duration of the igniter and the ignition delay were approximately $980 \mathrm{~ms}$ and $220 \mathrm{~ms}$, respectively. They were almost the same as prediction. It was confirmed that margin of ignition was enough, because the combustion duration of igniter is more than three times as long as the ignition delay.

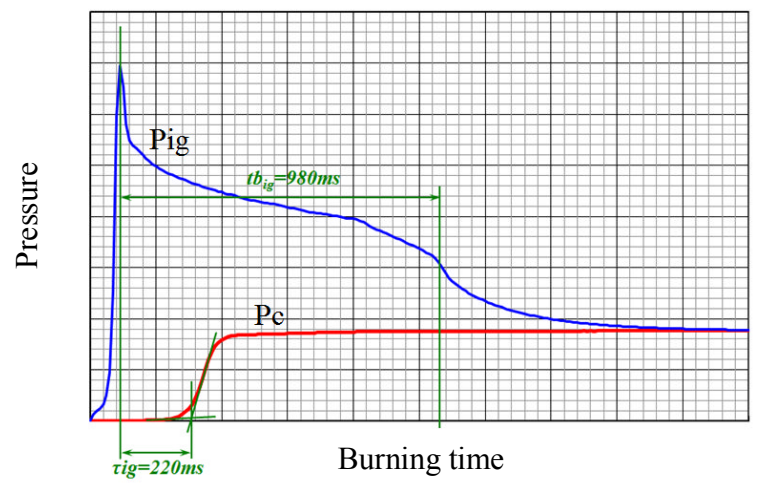

Fig. 4. Chamber pressure and igniter pressure in transition region at the ignition.

Chamber pressure profile is shown in Fig. 5. Vacuum thrust profile is shown in Fig. 6. The experimental data were calculated from the measured value with correcting choke profile, throat erosion profile and separation of the combustion gas flow. The experimental result was slightly higher than the prediction result. It was thought that the reason for this was prediction error of throat erosion profile and the propellant grain shape, which was changed by chamber pressure. Re-prediction was conducted with considering the prediction error. As a result, the experimental result was in good agreement with re-prediction. Therefore, it could be considered that the abnormal combustion did not occur. The evaluation results of propulsion characteristics are shown in Table 6 .

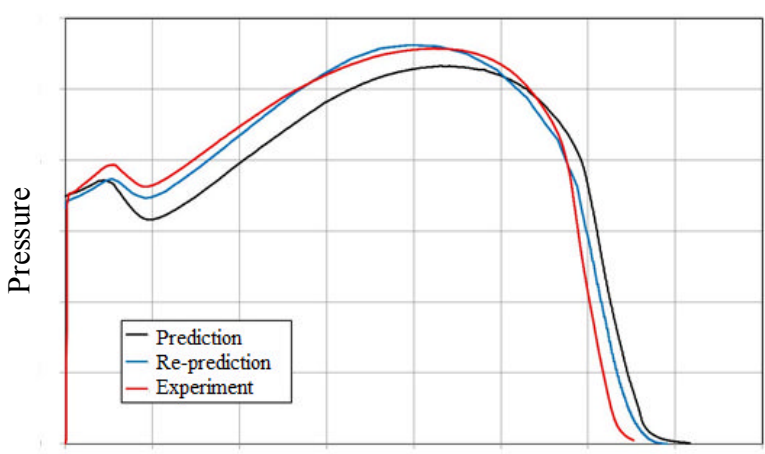

Burning time

Fig. 5. Chamber pressure profile.

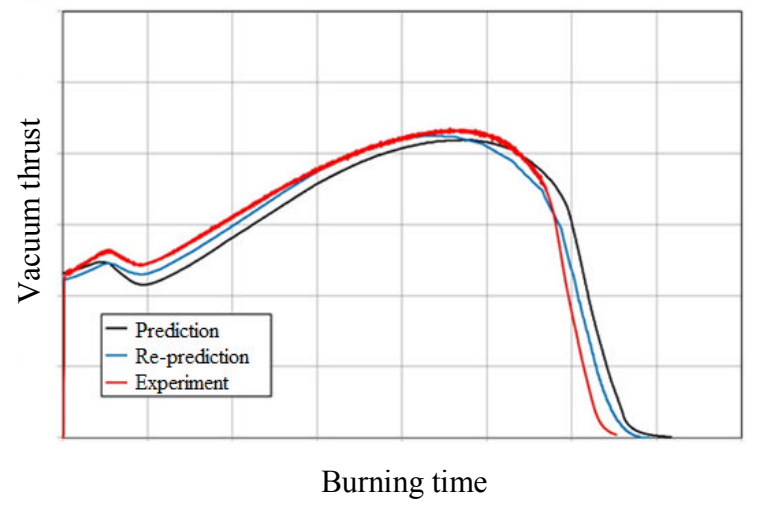

Fig. 6. Vacuum thrust profile.

Table 6. Evaluation results of propulsion characteristics.

\begin{tabular}{ll} 
Burning duration* & $129 \mathrm{~s}$ \\
\hline Average chamber pressure & $4.7 \mathrm{MPa}$ \\
\hline Average vacuum thrust & $346 \mathrm{kN}$ \\
\hline Average vacuum specific impulse & $282 \mathrm{~s}$ \\
\hline
\end{tabular}

Other confirmation items are shown below.

- The TVC nozzle actuated with following the command. There was no problem.

- The diffuser and the cooling water feed system functioned normally.

- It was confirmed that there was no problem with the appearance of the motor after test.

- Although some part of the measurement data was lost due to burning out of sensors by a back fire from diffuser, necessary data for the final verification were obtained.

The M-35 static firing test was successfully performed. The results of the test are reflected and the thickness of the case insulation and the basic burning rate of the propellant were redesigned. 


\section{Results of Propulsion System of the Second Flight of the Epsilon}

The JAXA successfully launched the second Epsilon Launch Vehicle with Exploration of energization and Radiation in Geospace (ERG) aboard at 8:00 p.m. on December 20, 2016 from the Uchinoura Space Center. It was the first flight of the Enhanced Epsilon launch vehicle. The launch vehicle flew as planned, and at approximately 13 minutes and 27 seconds after liftoff, the separation of ERG was confirmed.

Table 7 shows the sequence of event (SOE) of the second flight of the Epsilon launch vehicle (the first flight of the Enhanced Epsilon launch vehicle). Various telemeter data sent from the Epsilon launch vehicle were acquired well. Basic information for evaluation after the flight was obtained. As the result of the evaluation of the flight data, it was considered that all propulsion system operated normally.

Table 7. Sequence of Event of the second flight o
\begin{tabular}{ll}
\hline Time $[\mathrm{s}]$ & Event \\
\hline-10 & SMSJ ignition \\
\hline 0 (Lift off) & $1^{\text {st }}$ motor ignition \\
\hline 112 & $1^{\text {st }}$ motor burn-out \\
\hline 151 & Fairing separation \\
\hline 160 & $1 / 2$ separation \\
\hline 165 & $2^{\text {nd }}$ motor ignition \\
\hline 294 & $2^{\text {nd }}$ motor burn-out \\
\hline 397 & $2 / 3$ separation \\
\hline 401 & $3^{\text {rd }}$ motor ignition \\
\hline 491 & $3^{\text {rd }}$ motor burn-out \\
\hline 807 & Satellite separation \\
\hline
\end{tabular}

\section{1. $\quad 1^{\text {st }}$ stage propulsion system}

The $1^{\text {st }}$ stage main motor is SRB-A same as H-IIA and H-IIB launch vehicle. Two solid motor side jets (SMSJ), which are used for the roll control during the first stage powered flight and the three-axis attitude control after the SRB-A burnout, are equipped on the outer surface of motor nozzle housing of the SRB-A. Figure 7 shows chamber pressure during the flight with chamber pressure predicted before the flight. As the result of evaluation of time history of the chamber pressure of the SRB-A, it was confirmed that the chamber performance was the same as the predicted results of SRB-A.

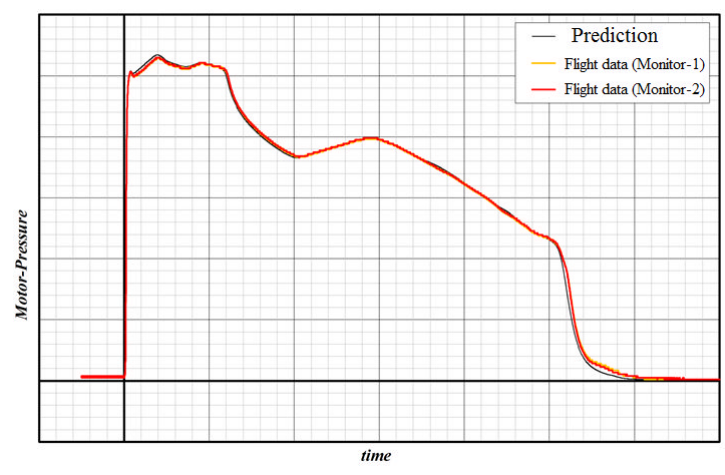

Fig. 7. Time history of chamber pressure of SRB-A.
The SMSJ consists of a solid propellant gas generator (SPGG) and a hot gas valve (HGV), which can control the direction of the hot gas. Figure 8 shows two SMSJs' SPGG and HGV pressure during the flight with the pressures predicted before the flight and the pressures of the Epsilon's first flight. As the result of the internal pressure of the SMSJs obtained during the flight, it was confirmed that the ignition 10 seconds before the lift-off was succeeded and the combustion was stable and the internal pressure was almost constant until burn-out.

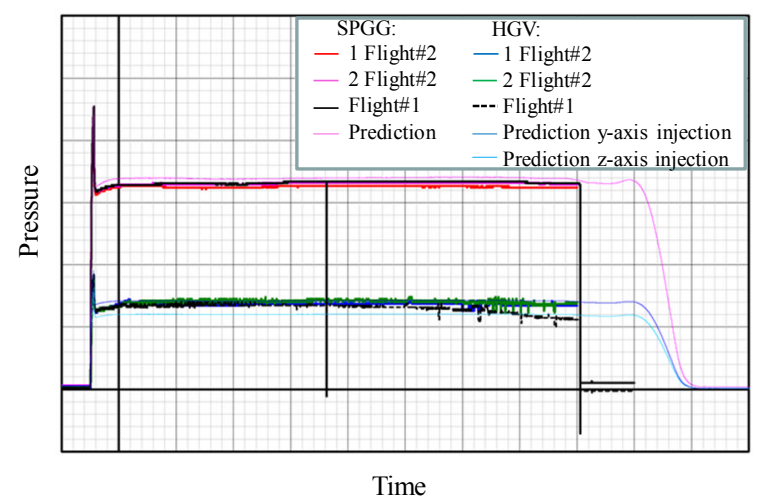

Fig. 8. SPGG and HGV pressure.

\section{2. $2^{\text {nd }}$ stage propulsion system}

The $2^{\text {nd }}$ stage main motor is M-35. Three-axis attitude control during the $2^{\text {nd }}$ stage powered flight is conducted with a movable nozzle thrust vector control (MNTVC) system of the main motor. Two reaction control systems (RCS), which are mono-propellant gas jet (GJ) systems, are used for roll attitude control during the $2^{\text {nd }}$ stage powered flight and three-axis attitude control from the main motor burnout to the $2^{\text {nd }}$ stage separation. After the motor burnout, two spin motors (SPMs) operate to spinning the $3^{\text {rd }}$ stage.

Figure 9 shows chamber pressure during the flight with chamber pressure predicted before the flight. The second half of the chamber pressure during the flight was a little smaller than the prediction. It was thought that the reason for this was that the erosion rate of the nozzle was a little greater than the prediction. So, the flight data was re-estimated. As the result of the re-prediction, the flight data were in good agreement with the re-prediction data. Figure 10 shows the vacuum thrust predicted from the chamber pressure and that from the acceleration data. These two data were almost same. As the result of evaluating the flight path based on the longitudinal acceleration data, it is confirmed that the delta- $\mathrm{V}$ of the $2^{\text {nd }}$ stage corresponds to the planned value.

\section{3. $\quad 3^{\text {rd }}$ stage propulsion system}

The $3^{\text {rd }}$ stage main motor is KM-V2c. It inherits the basic design of the KM-V2 developed for the fifth $\mathrm{M}-\mathrm{V}$ rocket $^{5)}$ as a kick-stage motor, which had successfully injected the Japanese space probe Hayabusa into an interplanetary orbit. It is remanufactured with current production technologies. The specification of the nozzle was changed with reconsideration of the configuration of the launch vehicle in the Enhanced Epsilon Project. Figure 11 shows schematic of the $3^{\text {rd }}$ stage 
main motor. Considering the balance between cost and performance, the extendable system of the nozzle is not adopted and the nozzle expansion ratio is redesigned.

As the result of evaluating the flight path based on the longitudinal acceleration data, it is confirmed that the delta- $\mathrm{V}$ of the $3^{\text {rd }}$ stage corresponds to the planned value.

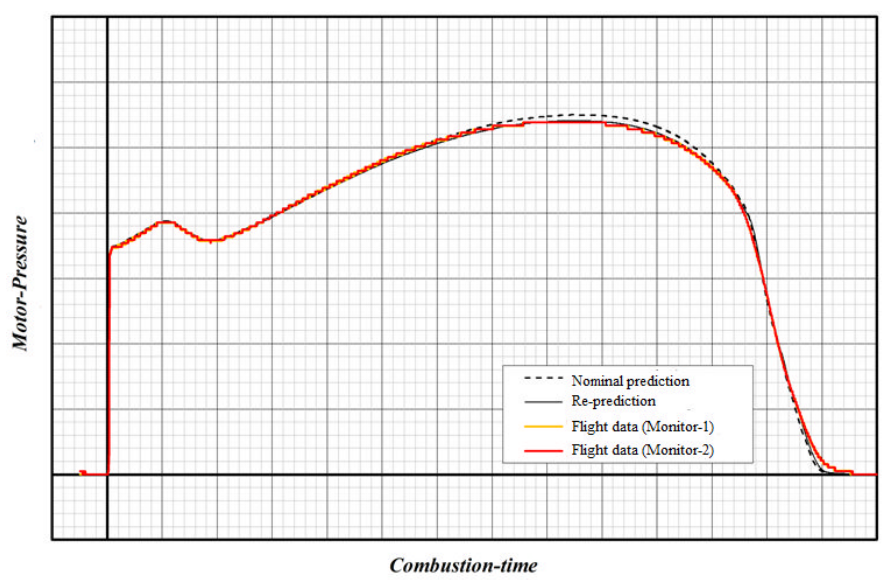

Fig. 9. Time history of chamber pressure of M-35.

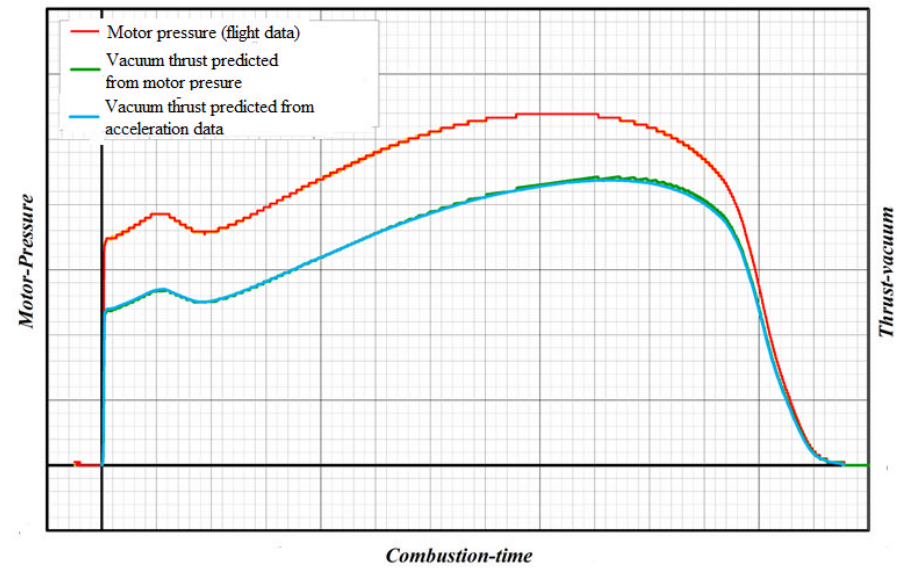

Fig. 10. Time history of vacuum thrust of M-35.

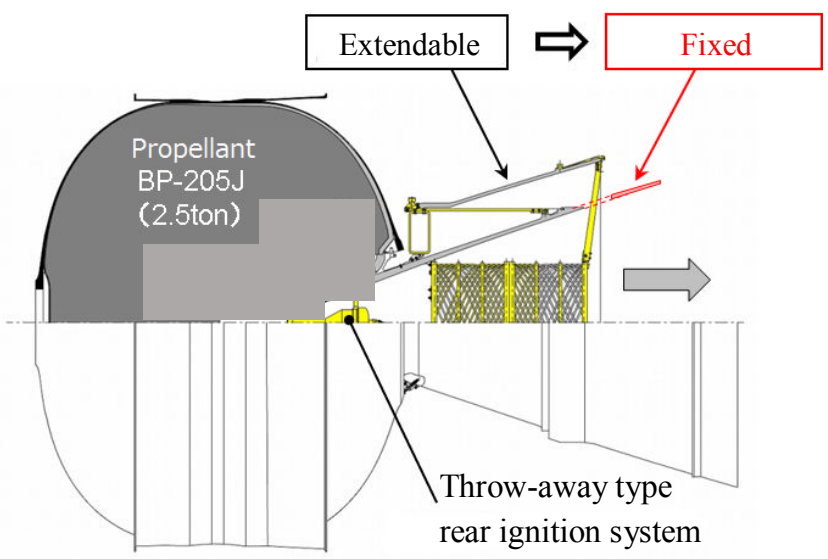

Fig. 11. Schematic of $3^{\text {rd }}$ stage main motor. ${ }^{3)}$

\section{Conclusion}

The development of enhanced propulsion system for the next Epsilon rocket was progressed. The development of Enhanced Epsilon is mainly the renewal of the second stage, and also includes each subsystem's improvement. The main change of the solid propulsion system is exposure of the second stage motor. The second stage motor M-35 was newly designed and manufactured. The outside diameter of the motor case is expanded to approximately $2.6 \mathrm{~m}$ in order to increase the acceptable amount of the solid propellant and the outer shell of the motor case is used as the outer shell of the launch vehicle. Solid propellant which can be the high-performance equal to a conventional upper-stage motor developed newly, with cost reduction.

In order to verify the design, the static firing test of the second motor M-35 under the condition of vacuum ambient was conducted. The static firing test was successfully performed at Noshiro rocket testing center in December, 2015. The propulsion performance was good. The results of the test were reflected.

The JAXA launched the first Enhanced Epsilon launch vehicle with Exploration of energization and Radiation in Geospace (ERG) aboard in December, 2016. All solid propulsion systems for the Enhanced Epsilon launch vehicle showed a very good behavior during the flight.

\section{References}

1) Morita, Y., Imoto, T., and Ohtsuka, H.: Development of Japan's Next Generation Solid Rocket Launcher - the Epsilon Rocket, 61 st Congress of the International Astronautical Federation (IAC), Prague, Czech Republic, IAC10.D2.1.7, 2010.

2) Morita, Y., Imoto, T., Habu, H., and Ohtsuka, H.: Japan's Next Generation Solid Rocket Launcher, 60th Congress of the International Astronautical Federation (IAC), Daejeon, Republic of Korea, IAC-09.D2.1.9, 2009.

3) Kitagawa, K., Tokudome, S., Hori, K., Habu, H., Wada, E., Tannno, H., and Nakano, N.: Development Status of Solid Propulsion System for Enhanced Epsilon Launch Vehicle, 30th International Symposium on Space Technology and Science, Kobe, Japan, ISTS-2015-g-12, 2015

4) Kitagawa, K., Tokudome, S., Hori, K., Tannno, H., and Nakano, N.: Development of Solid Propulsion System for Enhanced Epsilon Launch Vehicle and M-35 Static Firing Test, 67th Congress of the International Astronautical Federation (IAC), Guadalajara, MExico, 2016, Paper No. IAC-16-C4.2.6.

5) ISAS/JAXA: The M-V Rockets: From the Fifth to the Eighth Vehicle, JAXA-SP-07-023, JAXA, 2008.

https://repository.exst.jaxa.jp/dspace/bitstream/a-is/41247/1/64112 000.pdf (in Japanese) (accessed June 1, 2017). 